\title{
Teaching methodologies to promote creativity in the professional skills related to optics knowledge
}

\section{Alicia Fernández-Oliveras, Paz Fernandez, Antonio Peña- García, Maria Oliveras}

Alicia Fernández-Oliveras, Paz Fernandez, Antonio Peña-García, Maria Luisa Oliveras, "Teaching methodologies to promote creativity in the professional skills related to optics knowledge," Proc. SPIE 9289, 12th Education and Training in Optics and Photonics Conference, 928910 (17 July 2014); doi: $10.1117 / 12.2070754$

SPIE Event: 12th Education and Training in Optics and Photonics Conference, 2013, Porto, Portugal 


\title{
Teaching methodologies to promote creativity in the professional skills related to optics knowledge
}

\author{
Alicia Fernández-Oliveras ${ }^{1}$, Paz Fernandez ${ }^{2}$, Antonio Peña-García ${ }^{2}$, María Luisa Oliveras ${ }^{3}$ \\ ${ }^{1}$ Departamento de Didáctica de las Ciencias Experimentales, Facultad de Ciencias de la Educación, \\ Universidad de Granada, Campus de Cartuja. 18071 Granada (SPAIN) \\ ${ }^{2}$ Departamento de Ingeniería Civil, Escuela Técnica Superior de Ingeniería de Caminos, Canales y \\ Puertos, Universidad de Granada, Campus Fuentenueva. 18071 Granada (SPAIN) \\ ${ }^{3}$ Departamento de Didáctica de las Matemáticas, Facultad de Ciencias de la Educación, Universidad \\ de Granada, Campus de Cartuja. 18071 Granada (SPAIN)
}

\begin{abstract}
We present the methodologies proposed and applied in the context of a teaching-innovation project developed at the University of Granada, Spain. The main objective of the project is the implementation of teaching methodologies that promote the creativity in the learning process and, subsequently, in the acquisition of professional skills. This project involves two subjects related with optics knowledge in undergraduate students. The subjects are "Illumination Engineering” (Bachelor's degree in Civil-Engineering) and "Optical and Optometric Instrumentation” (Bachelor's degree in and Optics and Optometry). For the first subject, the activities of our project were carried out in the theoretical classes. By contrast, in the case of the second subject, such activities were designed for the laboratory sessions. For "Illumination Engineering" we applied the maieutic technique. With this method the students were encouraged to establish relationships between the main applications of the subject and concepts that apparently unrelated with the subject framework. By means of several examples, the students became aware of the importance of cross-curricular and lateral thinking. We used the technique based on protocols of control and change in "Optical and Optometric Instrumentation". The modus operandi was focused on prompting the students to adopt the role of the professionals and to pose questions to themselves concerning the practical content of the subject from that professional role. This mechanism boosted the critical capacity and the independent-learning ability of the students. In this work, we describe in detail both subject proposals and the results of their application in the 2011-2012 academic course.
\end{abstract}

Keywords: optics knowledge in undergraduate students, teaching methodologies, professional skills, creativity, crosscurricular teaching, lateral thinking, critical capacity.

\section{INTRODUCTION}

The signing of the Bologna Declaration laid the foundation for the development of a common sphere of learning , in the spirit of European integration. Under the aegis of the European Higher Education Area (EHEA), Spanish universities are moving towards new models of teaching and learning. Since this change affects not only the structural arrangement but also teaching dynamics, the introduction and implementation of new teaching methodologies is required. ${ }^{1}$ In this context, the pedagogical systems of the university demand novel and innovative approaches which assist the acquisition of professional skills.

To guarantee that students are prepared beyond the academic environment, their university training should take into account professional skills based on the creativity and critical thinking. Students of engineering and technical degrees need to be prepared to transcend literal and technical knowledge to generate creative thoughts and thereby meet the challenge of unpredictable operational tasks. ${ }^{2}$

*alilia@ugr.es; phone (34) 958243976; fax (34) 958243555

12th Education and Training in Optics and Photonics Conference, edited by

Manuel F. P. C. Martins Costa, Mourad Zghal, Proc. of SPIE Vol. 9289, 928910

(c) 2014 SPIE, OSA, IEEE, ICO · doi: 10.1117/12.2070754

Proc. of SPIE Vol. $9289928910-1$ 
In scientific and technical subjects in higher education, it is usually difficult to draw students' attention to the reflection and metacognition because mathematical approaches and exercises are often used without delving into the causes and consequences of actions. Hence, it is important to set objectives to stir the students' lateral thinking, their own enthusiasm for the ability to solve diverse problems, and their self-management of intellectual and professional growth. In this framework, motivational tools are required to capture the interest of trainees with the goal of generating creative thinking.

In previous works, pedagogical changes based on innovative methodologies were sought. ${ }^{3-8}$ This experience has led our interdisciplinary group to work together and face the present requirements of our university. In this work, we present the methodologies proposed and applied in the context of a teaching-innovation project developed at the University of Granada, Spain. This project involves two subjects related to knowledge of Optics among students of the Bachelor's degree in Civil Engineering and the Bachelor's degree in Optics and Optometry. The aim of the project was to implement teaching methodologies that promote creativity in the learning process and, subsequently, in the acquisition of professional skills.

\section{CREATIVITY AND PROFESSIONAL SKILLS}

High education quality does not have an established and closed pattern. Its value lies in the ability to control, review, critique, and continuously update information. Excellent professionals, after studying at the university, keep updating their knowledge throughout their entire professional life. Making lifelong learning a reality implies promoting creativity. ${ }^{9}$ From an open and extensive concept of creativity, we believe that experts such as optometrists and engineers have several sources of lifelong learning, such as the self-control in administering their own knowledge and in the relationships that may be established between this knowledge and real-life situations.

Our proposal involves on a theoretical characterization of creativity based on some indicators specially adapted from a fuzzy mathematical model used for evaluating professionals skills elsewhere. ${ }^{10}$ These signs or indicators comprise diverse facets of creativity and the following:

- Maintaining flexibility of thought.

- Searching for alternative methods to solve problems.

- Establishing new working hypotheses.

- Exploring new sources of information.

- Proposing new interpretations of the errors and deadlocks at work.

- Applying specific methods or theories from one particular field to another.

- Adapting of systems or tools to new uses.

- Creating new theoretical or instrumental elements based on existing ones.

- Drawing non-trivial conclusions.

- Developing intuition concerning potential novelty in a field of study.

- Establishing relationships between the abstract and concrete.

- Integrating various scientific and technological fields in the development of new projects.

- Expressing the personal thoughts in social terms, with reference to scientific or technological concepts.

The above creativity indicators were the guidelines to set the specific objectives to be achieved with our project (listed in Table 1).

\section{METHODOLOGY}

The methodology developed includes different techniques that were adapted to the specific curriculum of each subject involved in the project. The techniques have a common social-constructivist cognitive background, in which knowledge is considered to be a construct achieved through social consensus among equals in the interaction between students and teacher. This interaction was undertaken in small work groups (2-3 students), medium-sized work groups (group of practices that range from 15 to 30 students depending on the subject), and large group (class of 60 to 90 students).

This project involved two subjects related to Optics for undergraduate students: "Illumination Engineering" (Bachelor’s degree in Civil Engineering) and “Optical and Optometric Instrumentation” (Bachelor’s degree in and 
Optics and Optometry). For the first subject, the activities of our project were conducted in the theory classes. By contrast, in the case of the second subject, such activities were designed for the laboratory sessions.

\subsection{Illumination Engineering (Bachelor’s degree in Civil Engineering)}

Civil engineers must be able to solve unexpected and complex problems in their professional life. However, Civil Engineering students may think that being creative is not so important for their career and therefore they may not be as interested in cross-curricular subjects, such as "Illumination Engineering", as in other subjects traditionally related with Civil Engineering. Our project focused on enhancing lateral thinking and creativity development among the Civil Engineering students, by giving them a more active role in the teaching and learning process. With this aim, we applied the maieutic technique.

In this method, the theme of the lesson was made up of a sequence of questions selected by the teacher. First, a question that was seemingly nonsensical and outside the context of the subject was posed. Potential answers were discussed and debated (with guidance from the teacher), and then the next question was asked based on the dialogue generated. Finally, the students had to find the relationship between the questions and the goals of the class, and were expected to reflect on the implications and applicability to real cases of professional practice and daily life. During process, the teacher promoted participation and expression of ideas by all students involved in the experience. The aim was, according to Lipman ${ }^{11}$, to turn the classroom into a "research community", in which students listen to and show respect for each other while building their ideas on those of others. The intention was for the attitude of the students to develop from the astonishment or surprise, to passionate participation.

\subsection{Optical and Optometric Instrumentation (Bachelor's degree in and Optics and Optometry)}

Optometrists and Opticians as professionals must bring together two different but complementary lines: on the one hand, they need to be able to solve scientific problems related to Optics, and on the other, they should be healthcare professionals who provide primary vision care. Therefore, the range of skills needed to define their profession is extremely broad and varied. Our project focuses on those requiring higher amounts of creativity:

1. Thinking critically about clinical, scientific, and social ethics involved in the practice of Optometry, while understanding the scientific basis of Optics and Optometry. Optometry

2. Critically evaluating the terminology, clinical trials and research methodology related to Optics and

3. Delivering expert opinions and appropriate optometric reports when necessary. profession.

4. Judging and incorporating technological improvements necessary for the proper development of their

5. Planning and carrying out research projects that contribute to the production of knowledge in the field of Optometry, transmitting scientific knowledge by conventional means.

6. Locating new information and interpreting it in a given context. disciplines.

7. Understanding the general structure of Optometry and its connection with other specific and complementary

8. Demonstrating and implementing methods of critical analysis, developing theories and their application to the discipline of Optometry.

9. Participating effectively in work groups and multidisciplinary projects related to Optometry.

In addition to the former professional skills, listed in the Order CIN/727/2009, our project also placed attention on certain cross-curricular skills related to creativity:

- Ability to communicate orally and in writing.

- Facility to manage information.

- Capability to solve problems.

- Aptitude to work in team.

- Capacity to develop critical thinking.

- Initiative to develop independent learning. 
In the syllabus of the Bachelor's degree in and Optics and Optometry, the subject "Optical and Optometric Instrumentation" is described as "Design, manufacturing, quality control and adaption of optical instruments". The aim of the subject is to provide a basic and integral training in the instruments frequently used by Optometrists and Opticians. In this context, the laboratory sessions complement knowledge concerning backgrounds, composition, characteristics, and applications of optometric and optical instruments in order to help the students implement this knowledge. Instrumental design and manufacturing is broadly treated in theory classes but quality control and adaption are undertaken only in the laboratory sessions. Critical thinking and creativity are displayed in the laboratory, where different devices have errors that evidence the validity range that theory has in practice.

We used the technique based on protocols of control and change. The modus operandi was focused on prompting the students to adopt the role of the professionals and to raise questions to themselves concerning the practical content of the subject from the standpoint of that professional role. The goal was for the student, by brief questions, to be able to detect the key points for the report related to each laboratory set-up.

The questions focused on: detecting weaknesses in the experimental devices of each practice (quality-control test), comparing theory with practical application (assessment of divergence between theory and its application to actual experimental devices) and create variants of the practices (changes in the method or in the device to adapt it to other uses, to improve parameters or optimise variables involved). Proposed issues were worked on individually or in small groups in order to foster independent learning or teamwork.

\section{LEARNING RESULTS}

The results of the activities undertaken in this project that was focused on the professional skills related to Optics were quite successful, and pleasing to students and also to us as teachers. Table 1 summarizes the learning results achieved by the students in relation to the specific objectives pursued.

Table 1. Students' benefits of the teaching-innovation project, related with the specific objectives pursued.

\begin{tabular}{|l|l|}
\hline Objective pursued & Learning results achieved by the students \\
\hline $\begin{array}{l}\text { Encourage lateral } \\
\text { thinking }\end{array}$ & $\begin{array}{l}\text { - The students established relationships between the main applications of the subject } \\
\text { and concepts that apparently unrelated with the subject framework. } \\
\text { • They listened to each other, showed respect and built their ideas on those of others. }\end{array}$ \\
\hline $\begin{array}{l}\text { Stimulate the building of } \\
\text { new ideas and proposal } \\
\text { of innovative projects }\end{array}$ & $\begin{array}{l}\text {-The students felt able to evaluate and make decisions on difficulties in practical } \\
\text { situations. } \\
\text { - They sought answers to problems without thinking about the "right" answer expected } \\
\text { by the teacher. }\end{array}$ \\
\hline $\begin{array}{l}\text { Strengthen the } \\
\text { theoretical analysis } \\
\text { applied to the resolution } \\
\text { of professional problems }\end{array}$ & $\begin{array}{l}\text {-The students were able to adopt the role of the professionals and to pose questions to } \\
\text { themselves from that professional role. }\end{array}$ \\
\hline $\begin{array}{l}\text { Boost the capacity for } \\
\text { integrating knowledge } \\
\text { from different areas to } \\
\text { confront professional } \\
\text { real-life cases }\end{array}$ & $\begin{array}{l}\text {-The students reflected on prior knowledge while seeking answers to other questions } \\
\text { related to the development of their future profession. } \\
\text { - They formed the habit of not limiting themselves only to the subject itself, trying } \\
\text { creatively to establish relationships between different contexts. }\end{array}$ \\
\hline $\begin{array}{l}\text { Develop scientifically } \\
\text { based critical thinking } \\
\text { and the capacity to make } \\
\text { well-founded } \\
\text { assessments }\end{array}$ & $\begin{array}{l}\text { - By making revisions and drawing conclusions based on objective data, the students } \\
\text { developed scientifically based critical thinking }\end{array}$ \\
\hline $\begin{array}{l}\text { Enrich the forms of } \\
\text { scientific expression }\end{array}$ & $\begin{array}{l}\text { • The students made a framework of scientific discussion. } \\
\text { express scientific ideas and concepts. }\end{array}$ \\
\hline
\end{tabular}




\section{CONCLUSIONS AND FUTURE WORK}

In this work, we present the methodologies proposed and applied in the context of a teaching-innovation project developed at the University of Granada, Spain. The main objective of the project was to implement teaching methodologies that promote the creativity in the learning process and, subsequently, in the acquisition of professional skills.

This project involves two subjects related with optics knowledge in undergraduate students: "Illumination Engineering” (Bachelor's degree in Civil Engineering) and “Optical and Optometric Instrumentation” (Bachelor's degree in and Optics and Optometry).

For "Illumination Engineering”, we applied the maieutic technique. With this method the students were encouraged to establish relationships between the main applications of the subject and concepts that were apparently unrelated to the subject framework. By means of several examples, the students became aware of the importance of cross-curricular and lateral thinking. We used the technique based on protocols of control and change in "Optical and Optometric Instrumentation”. The modus operandi was focused on prompting the students to adopt the role of the professionals and to ask themselves questions concerning the practical content of the subject from that professional role. This mechanism boosted the critical capacity and the independent-learning ability of the students.

The activities undertaken in this project that were focused on the professional skills related to Optics were quite successful, and pleasing to students as well as to the teachers. The results were in general very positive, during the execution itself and in the follow-up activity carried out by the students. At the end of our activities a series of enquiries were delivered to the students which were asked to be returned for analysis and statistical treatment. Currently, we are engaged in extending the present work to another teaching-innovation project which also includes professional skills related to optics knowledge. In the very near future, when both projects are finished, we will complete the statistical analysis of the surveys.

\section{ACKNOWLEDGMENTS}

The authors express their appreciation to the Vicerrectorado de Ordenación Académica y Profesorado de la Universidad de Granada, Spain, for financing teaching-innovation projects 11-212 and 12-124 under María Luisa Oliveras and Paz Fernandez coordination.

\section{REFERENCES}

[1] De Miguel Díaz, M., Alfaro Rocher, I. J., Apodaca Urquijo, P., Arias Blanco, J. M., García Jiménez, E, Lobato Fraile, C., and Pérez Boullosa, A., [Modalidades de enseñanza centradas en el desarrollo de competencias. Orientaciones para promover el cambio metodológico en el espacio europeo de educación superior], Ediciones de la Universidad de Oviedo, Oviedo (2006).

[2] García-Restrepo, C. P., Undergraduate thesis, Más allá de la hermenéutica y la mayéutica: el pensamiento creativo, Universidad de Antioquia, Medellín, 2011.

[3] Benitez Funes, J., Fernández Oliveras, P., Espín Estrella, A., Iglesias Precioso, M., and Oliveras Contreras, M.L., [Matemáticas en la Sociedad], Fuentes Ramírez J. y Oliveras Contreras M. L. Ed., Granada (2000).

[4] Oliveras, M. L., “Microproyectos para la educación intercultural en Europa,” Revista UNO 38, 70-81 (2005).

[5] Oliveras, M. L., “Etnomatemáticas. De la multiculturalidad al mestizaje,” Biblioteca de UNO 232, 117-149 (2006).

[6] Oliveras, M. L., Cardeñoso, J. M., Molina, M. and Servín, C., "Use of Integrated Projects in a Mathematics Education Course for Prospective Kindergarten Teachers,” International Journal of Interdisciplinary Social Sciences 2(6), 165-174 (2008). 
[7] Oliveras, M. L. and Gavarrete, M. L., “Modelo de aplicación de etnomatemáticas en la formación de profesores para contextos indígenas en Costa Rica,” RELIME. Revista latinoamericana de investigación en matemática educativa 15(3), 339-372 (2012).

[8] Oliveras, M. L. and Albanese, V., "Etnomatemáticas en artesanías de trenzado: un modelo metodológico para investigación,” BOLEMA. Boletim de Educaçào Matemática 26 (44), 1315-1344 (2013).

[9] European Commission, Lifelong Learning Programme: Creativity and Innovation International, Office for Official Publications of the European Communities, Luxembourg, 2009.

[10] Oliveras, M. L., "Ethnomathematics and Mathematical Education,” ZDM International Reviews on Mathematical Education 20517F (3), 85-91 (1999).

[11] Lipman, M., [Philosophy in the Classroom], Temple University Press, Philadelphia (1980). 